\title{
Variation in the Multivariate Relationships Between Serum Amyloid, Haptoglobin and Biochemical Profiles of Aborted and Non-Aborted Cows
}

\author{
Gädicke $P_{,}^{1}$ Letelier $R^{1 *}$ Chihuailaf $R_{,}{ }^{2}$ Ruiz $A,{ }^{2}$ Junod $T^{3}$ \\ ${ }^{1}$ Departamento de Patología y Medicina Preventiva, Universidad de Concepción, Chile \\ ${ }^{2}$ Instituto de Ciencias Clínicas, Universidad Austral de Chile, Chile \\ ${ }^{3}$ Universidad Santo Tomas, Chile
}

\begin{abstract}
Because the time in which gestational loss or bovine abortion occurs is associated with multifactorial causes, the objective of this study was to assess multivariate relationships between the biochemical profile and acute phase proteins in aborted cows. We performed monitoring and monthly blood sampling during gestation in 140 dairy cows. A total of 18 cows aborted, which were considered 'cases'; retrospectively, we used samples from 29 'control' cows, which were taken at the same time. Thus, we compared multivariate relationships between the two groups, to evaluate variables potentially associated with cow abortion. We classified abortion as either infectious (due to DVB, leptospirosis or neosporosis) or non-infectious (protein or energetic imbalance evinced in metabolic profile). Of the 18 cows that aborted, there were 6 with evidence of positivity or seroconversion to the analysed diseases, 13 with evidence of metabolic protein imbalances, 7 with evidence of energy imbalances and 10 of them with combined situations.
\end{abstract}

Case and control cows have significant differences $(\mathrm{p}<0.05)$ between their Principal Component Analysis (PCA), indicating that the two groups have different multivariate relationships. In aborted cows we identified a grouping of variables referring to protein metabolism asFibrinogen, Serum amyloid A, haptoglobin and titres for neosporosis and bovine viral diarrhoea virus; separated from others referring to energy and protein imbalance ashigh beta-hydroxy-butyrate, low cholesterol, low total protein. However, serum amyloid A and haptoglobin were not increased in aborted cows with clues of infectious diseases such as bovine viral diarrhoea virus, leptospirosis or neosporosis.

In this way, it is evident that when the causality of abortions in a herd is studied, not only is it necessary to look for infectious diseases, but non-infectious causes can also be found occurring in parallel way. Serum amyloid A could be a candidate biomarker to differentiate a non-infectious abortion.

Keywords: Bovine abortion syndrome, Haptoglobin, Serum amyloid, Infectious diseases, Cows

Abbreviations: PCA: Principal Component Analysis; BVD: Bovine Viral Diarrhoea; BAS: Bovine Abortion Syndrome; SAA: Serum Amyloid A; Hp: Haptoglobin; BHB: Beta Hydroxy Butyrate; IR: Reference Intervals

Highlights

- We studied the various factors that may cause cows to have abortions.

- $\quad$ Aborted cows present different relationships with the biochemical factors tested.

- Cows whose abortions relate to energy metabolic imbalance present more haptoglobin.

- Cows with contagious abortions did not increase serum amyloid A and haptoglobin.

Quick Response Code:

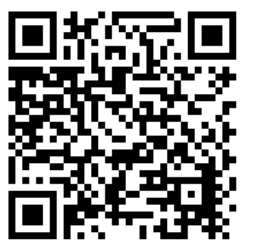

*Corresponding author: Letelier R,Avenida Vicente Méndez 595 Chillán, Departamento de Patología y Medicina Preventiva, Facultad de Ciencias Veterinarias, Universidad de Concepción, Chile

Received: 16 October, 2020

Published: 11 January, 2021

Citation: Gädicke P,Letelier R, Chihuailaf R, RuizA, Junod T. Variation in the Multivariate Relationships Between Serum Amyloid, Haptoglobin and Biochemical Profiles of Aborted and Non-Aborted Cows. SOJ Dairy Vet Sci. 2021;1(1):1-6. DOI: 10.53902/SOJDVS.2021.01.000501 


\section{Introduction}

There are several management tools available to accurately control, evaluate and diagnose a dairy farm, such as the use of productive and reproductive records, as well as laboratory tests (biochemical profiles). When these factors are analysed and used in the correct way, it allows us to detect a system's main flaws. Identifying weaknesses and critical points enable us to take corrective measures, thus increasing the company's productivity. ${ }^{1}$

Cow abortions can occur at different times: between conception and maternal recognition (days 16 to 19)considered early embryonic loss; between maternal recognition and the conclusion of differentiation or organogenesis (around day 42)called late embryonic loss, between days 42 and 260 of gestationconsidered foetal death. ${ }^{2}$ Since abortion cases are multifactorial, it is difficult to determine the causative agent, as gestational losses can be sporadic, endemic, can represent an outbreak, and can be of infectious origin (diseases such as bovine viral diarrhoea (BVD), leptospirosis, brucellosis, neosporosis, among others), and non-infectious origin (placentitis, vasculitis, thermal stress, among others). ${ }^{3}$ These factors can act both independently and collectively, reflected in the socalled Bovine Abortion Syndrome (BAS). ${ }^{4}$ Thus, to design tools that anticipate risk, we looked for early indicators related to biochemical alterations. Serum amyloid A (SAA) and haptoglobin (Hp) are proteins that indicate inflammation and infection in cattle. ${ }^{5}$

The objective of this study was to look for multivariate relationships of proteins in the acute phase or biochemical profiles in aborted cows. It has been suggested that, in dairy cows, proteins in the acute phase such as SAA and Hp, together with metabolic indicators of energy, oxidative, protein or organ integrity imbalance, have different relationships at the time of abortion. The main contribution of this study is the multivariate comparison between the 'cases' group of cows and the controls, assessing the variables potentially associated with abortion, which may reveal relationships between infectious and non-infectious factors.

\section{Materials and Methods}

We performed monthly blood sampling and monitoring during gestation, from day 42 until delivery or abortion. This was performed in a sample of 140 dairy cows of the Holstein Friesian cattle breed, in the Province of Ñuble, Chile. Of these, 18 aborted, which were considered "cases". We retrospectively took matched samples from 29 'control' cows, using the same sampling time for both groups.

In each sample, we evaluated gestation via ultrasonography and rectal palpation, and obtained blood samples for biochemical analysis. We analysed the plasma concentration of biochemical indicators such as Beta-Hydroxy-Butyrate (BHB), Cholesterol (Chol), Urea (U), Albumin (Alb), Globulins (Glob), Fibrinogen (Fib), Aspartate amino transferase (AAT), Calcium (Ca), Phosphorus (P), Total Proteins (Tp), Glutathione Peroxidase (Gpx) as well as Serum Amyloid A (SAA), Haptoglobin (Hp) and antibody levels (by ELISA) for Bovine Viral Diarrhoea (BVD) and Neosporosis (NEO).
We plotted endemic curves (median and quartiles 1 and 3) for the cows with complete gestation, using the reference intervals (IR) indicated by Wittwer. ${ }^{5}$ This classified abortions as infectious (due to DVB, leptospirosis or neosporosis) or non-infectious (protein or energetic imbalance found in the metabolic profile). We compared mean and median SAA and Hp plasma concentrations in either group, using parametric tests, non-parametric tests and 95\% confidence.

We grouped multivariate relationships between plasma concentrations of SAA, Hp, biochemical profile and disease antibodies via Principal Component Analysis (PCA), between the cases and control groups. We analysed partial correlation coefficients of the evaluated variables and their eigenvalue vectors (eigenvectors) in the principal components (PC) with greatest variance in data. PC1 and PC2 of the case and control cows were compared via the Kruskall-Wallis test, with 95\% significance, using the Stata 12 SE program.

\section{Results}

Of the 18 cows that aborted, 6 evidenced positivity or seroconversion to the diseases analysed (2 Leptospirosis, 4 Neosporosis), 13 evidenced protein metabolic imbalances or inflammation, 7 evidenced energy imbalances, and 10 evidenced combined imbalances - predominately energetic and inflammation.

The Hp plasma concentration before abortion was lower in control cows with a history of the diseases analysed (average $0.17 \mathrm{mg}$ / $\mathrm{ml}, \mathrm{p}=0.011$ ), than case cows without positivity or seroconversion to these diseases (average $0.38 \mathrm{mg} / \mathrm{ml}$ ). Similarly, SAA was lower in control cows with a serology for the analysed diseases (average $9.47 \mathrm{mg} / \mathrm{ml}, \mathrm{p}=0.005$ ), compared to cases cows without positivity or seroconversion to these diseases (average $10.01 \mathrm{mg} / \mathrm{ml}$ ). Then we found positive association of this acute phase proteins in non-infectious aborted cows. Aborted cows that evidenced protein imbalance demonstrated no differences in SAA or Hp plasma concentrations ( $p>0.05$ ). However, cows that evidenced energy imbalances in their metabolic profiles had higher Hp plasma concentration $(0.28 \mathrm{mg} / \mathrm{ml})$ before abortion $(\mathrm{p}<0.05)$.

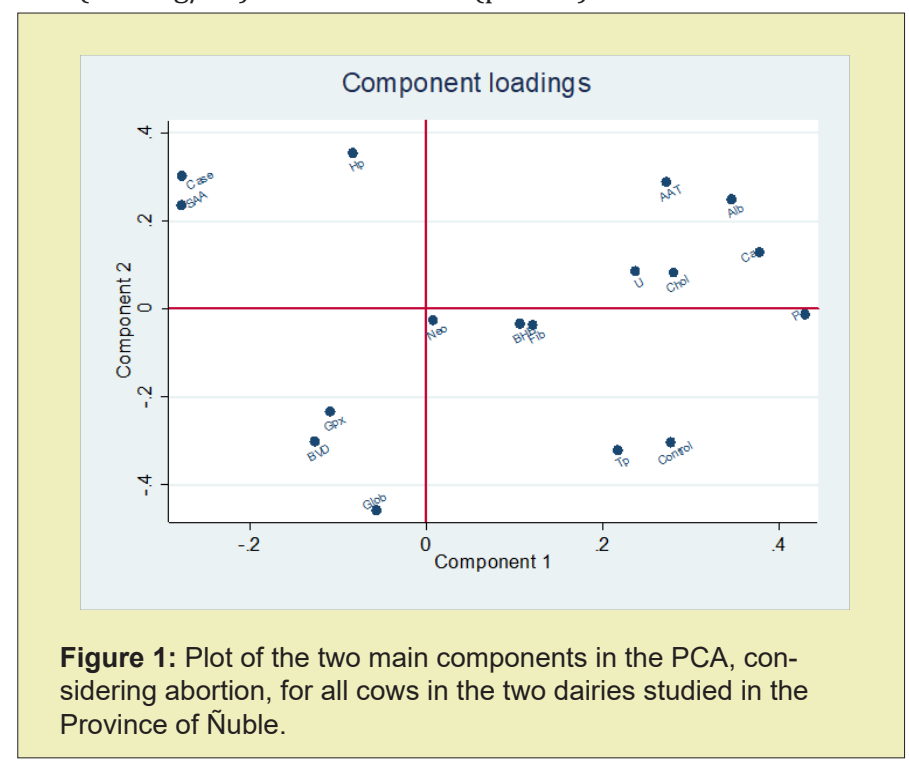


In the PCA for cows 'cases' and 'controls' together, the first four Principal Components (PC) grouped 58\% of the variability. PC1 was mainly represented by protein (Alb, Fib, U), energetic (Chol), organ integrity (AAT) imbalance indicators and the control cows. PC2 was mainly represented by proteins (Alb), acute phase proteins (SAA Hp) damage organs (AAT) and case cows. PC3 was mainly represented by energy and protein imbalances (Chol, BHB, Fib), good oxidative status (Gpx) and case cows. PC4 was mainly represented by protein imbalance (U, Tp, Glob), organ damage (AAT), title for prevalent infectious diseases (BVD, Neo) and 'case' cows. 'Case' cows have negative eigenvalues for PC1 and positive for PC2 with similar locations for SAA and Hp (Figure 1, upper left quadrant). Also, there were inverse relationship for SAA and Hp with the energetic metabolism (BHB) (Figure 1, oblique quadrants).

In the PCA for only 'cases' cows, the first four components grouped $68 \%$ of the variability. PC1 had positive eigenvectors for energetic-protein metabolism (BHB, Chol, $\mathrm{U}, \mathrm{Alb})$ and organ integrity (AAT) variables; also had important negative values for inflammatory proteins (Fib) and oxidative balance indicator (Gpx). For
$\mathrm{PC} 2$, there were positive values in protein (Tp, Glob) and energetic (BHB) metabolism imbalance indicators. PC3 is best represented by the infectious variables BVD and NEO. Finally, PC4 grouped inflammation proteins (SAA, Hp, Fib, Glob) and NEO titres. In the PCA for 'control' cows, the first four components grouped $67 \%$ of the variability. PC1 had positive eigenvectors for P, Ca, AAT, U, Chol; PC2 had positive values for Gpx, BVD, BHB; PC3 had positive value for $\mathrm{Tp}$, Glob; PC4 has positive value for Hp and Tp.

Comparing PC1 for cases and control analysis, there were significative differences $(\mathrm{p}<0.05)$. Protein balance $(\mathrm{Fib}, \mathrm{TP})$, oxidative balance (Gpx), acute phase protein ( $\mathrm{Hp}$ ) and energy balance (BHB) were the metabolites with greater absolute values of the differences (ABS) between the first components of the PCA of the case and control cows (Figure 2). Different associations of variables were found in both cow's groups. In the cases there was a closer relationship between AAT and Alb than in the controls. Also, in the cases the relationship between SAA, Hp, Fib, Gpx was closer than in the controls.

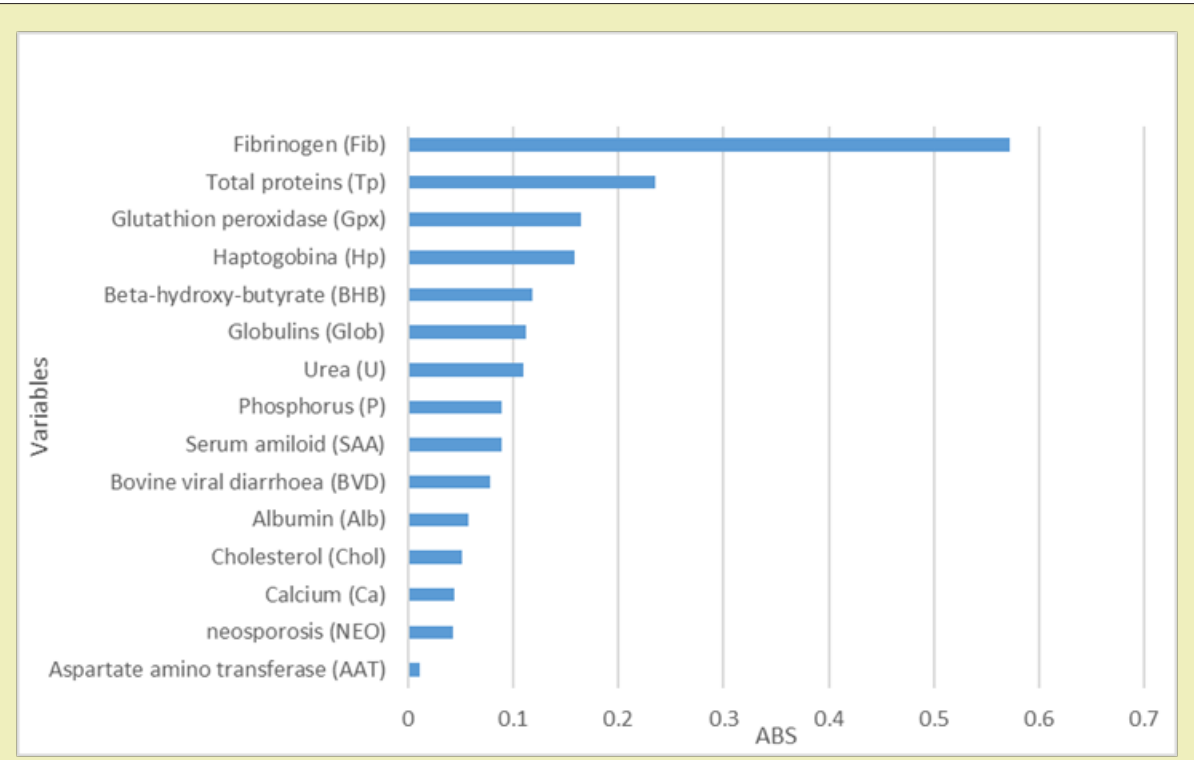

Figure 2: Absolute value (ABS) of the difference between the first components of the PCA of the case and control cows.

\section{Discussion}

As can be seen from the multivariate analyses of the case and control cows, the main causal component in these herds is metabolic and secondly infectious. Was found one group with protein-energetic metabolism imbalances related to nutrition and inflammation, and another group with nutritional protein imbalances, organ damage and high antibody titres for NEO However, diseases such as BVD and NEO, although prevalent in the area did not have a strong relationship with the cases. ${ }^{6}$

Also, the analytical contribution of this work was the continuous monitoring during pregnancy, through serial analysis of metabolites, being able to separate the metabolic problems of the herd and the specific aborted cows Thus, it was possible to evaluate the multivariate relationship and compare them, through an observational epidemiological study of cases and controls. Due to that abor- tion has a multifactorial causality and it is defined as a syndrome, it's possibleto analyse causal variables with a methodology that allows identifying different relationships. ${ }^{6}$ The effect of abortion is not only important for the current gestation, but also significantly affects the reproductive indicators of the herd. ${ }^{7}$

In addition to the traditional use of indicators of biochemical profiles, are been sought molecules that would be biomarkers of infection or some important inflammation. This is how in herd health, acute phase proteins have been tested as biomarkers of infection or inflammation. ${ }^{8,9}$ When infections and tissue injuries exceed local defences, the organism reacts by activating a broad systemic response. ${ }^{8}$ We found high level of Hp in infectious aborted cows and SAA in non-infectious aborted cows, this makes these acute phase proteins candidates to quickly discriminate an infectious or non-infectious abortion. However, for the group of cows that evidenced 
energy imbalances in their metabolic profiles had higher Hp plasma concentration before abortion. These are tools for monitoring health and diagnosing diseases in production animal. ${ }^{9}$ Various researchers have analysed and studied acute phase proteins associated with infectious and inflammatory diseases in certain livestock populations. The main objective has been to characterise the protein response in condition associated with abortion, such as vasculitis, poor corpus luteum function, thrombosis, antigen antibody reaction. ${ }^{8}$

The multivariate relationship with BAS aetiology is reinforced by 2008-2011 data from the Sub-department for Epidemiological Surveillance in Chile's Agricultural and Livestock Service (SAG ServicioAgrícola y Ganadero). A total of 507 abortions were reported, of which, 68 were of non-infectious origin. ${ }^{10}$ Among the possible causes of non-infectious abortion, many factors can influence its

Table 1: PCA eigenvectors for 'case' cows in the two dairies studied in the Province of Nuble.

\begin{tabular}{|c|c|c|c|c|}
\hline Variable & PC1 & PC2 & PC3 & PC4 \\
\hline Albumin (Alb) & 0.379 & -0.294 & 0.175 & 0.044 \\
\hline Aspartate amino transferase (AAT) & 0.371 & -0.301 & -0.051 & -0.013 \\
\hline Beta-hydroxy-butyrate (BHB) & 0.118 & 0.474 & -0.232 & 0.001 \\
\hline Bovine viral diarrhea (BVD) & -0.179 & 0.044 & 0.449 & -0.089 \\
\hline Calcium (Ca) & 0.365 & -0.046 & 0.212 & -0.155 \\
\hline Cholesterol (Chol) & 0.256 & 0.025 & -0.35 & 0.328 \\
\hline Fibrinogen (Fib) & -0.334 & -0.23 & 0.177 & 0.35 \\
\hline Globulins (Glob) & -0.037 & 0.557 & -0.01 & 0.24 \\
\hline Glutathion peroxidase (Gpx) & -0.242 & 0.038 & -0.063 & -0.497 \\
\hline Haptogobina (Hp) & -0.005 & -0.293 & -0.427 & 0.245 \\
\hline neosporosis (NEO) & 0.008 & -0.047 & 0.408 & 0.344 \\
\hline Phosphorus (P) & 0.336 & -0.183 & 0.172 & -0.051 \\
\hline Serum amiloid (SAA) & -0.168 & -0.176 & -0.288 & 0.144 \\
\hline Total proteins (Tp) & 0.304 & 0.326 & 0.149 & 0.295 \\
\hline Urea $(U)$ & 0.263 & 0.056 & -0.156 & -0.378 \\
\hline
\end{tabular}

Table 2: PCA eigenvectors for 'control' cows in the two dairies in the Province of Nuble.

\begin{tabular}{|c|c|c|c|c|}
\hline Variable & PC1 & PC2 & PC3 & PC4 \\
\hline Albumin (Alb) & 0.322 & -0.228 & -0.212 & 0.178 \\
\hline Aspartate amino transferase (AAT) & 0.359 & 0.068 & 0.066 & 0.006 \\
\hline Beta-hydroxy-butyrate (BHB) & 0.236 & 0.377 & -0.286 & -0.016 \\
\hline Bovine viral diarrhea (BVD) & -0.1 & 0.422 & 0.078 & -0.2 \\
\hline Calcium (Ca) & 0.321 & -0.329 & 0.266 & -0.211 \\
\hline Cholesterol (Chol) & 0.307 & 0.224 & -0.397 & -0.07 \\
\hline Fibrinogen (Fib) & 0.238 & -0.017 & 0.121 & 0.1 \\
\hline Globulins (Glob) & -0.15 & 0.303 & 0.495 & 0.201 \\
\hline Glutathion peroxidase (Gpx) & -0.077 & 0.454 & -0.246 & 0.022 \\
\hline Haptogobina (Hp) & 0.153 & -0.206 & -0.125 & 0.392 \\
\hline neosporosis (NEO) & 0.05 & 0.028 & 0.182 & -0.676 \\
\hline Phosphorus (P) & 0.426 & 0.041 & 0.231 & -0.171 \\
\hline Serum amiloid (SAA) & -0.257 & -0.101 & -0.139 & 0.022 \\
\hline Total proteins (Tp) & 0.069 & 0.203 & 0.429 & 0.409 \\
\hline Urea (U) & 0.372 & 0.259 & 0.076 & 0.133 \\
\hline
\end{tabular}


For future studies, we propose improving the power of statistics to explore the specific causal mechanisms of energetic and protein metabolism alterations that influence abortion onset. ${ }^{16}$ This is mainly due to the low resultant $\mathrm{n}$ for the varied causal mechanisms of BAS. The biochemistry of the main infectious or non-infectious abortion causal patterns needs to be characterized by experimental studies. The role of nutrition and metabolic priorities in high production cows is increasingly important. ${ }^{17,18}$ Thus, we find that Fib and $\mathrm{Tp}$, two important indicators of protein metabolism, are lower in aborted cows, that would be related with nutrition facts (Figure 1). ${ }^{18}$ On the other hand, it is interesting that control cows maintain an adequate level of Chol, while those with abortion have a lower level, which could be related to the metabolism of progesterone and the maintenance of pregnancy.

It would be very useful to have metabolic predictors related to reproductive performance that can serve as early warning. ${ }^{19,20}$ The various hormonal and metabolic signals from the liver, pancreas, muscle, and adipose tissue act on brain centres to regulate food consumption, energy balance and metabolism. ${ }^{20,21}$ Since this regulation can influence gestation, research has found that metabolic alterations associated with nutrition and energy requirements negatively affect reproductive performance in herds. ${ }^{22,23}$

Aetiological identification in cow abortion is a difficult task for veterinarians. An integrated approach is essential for the successful diagnosis of fertility and/or abortion problems in a herd. ${ }^{21}$ Inflammatory proteins help restore homeostasis, reduce microbial growth and have been used as inflammation, infection, and trauma biomarkers. ${ }^{24}$

\section{Conclusion}

The relationships between multivariate components demonstrate various possible metabolic imbalances found in aborted cows under intensive production in the Province of Nuble, amongst which we identified energetic and protein imbalances.

Aborted cows presented greater alterations in the negative energetic balance and liver integrity affected by fat mobilisation. The multivariate relationship between SAA, Hp, and biochemical variables were different in aborted cows; we identified a grouping of variables referring to protein metabolism as high concentrations of Fib, SAA, Hp, and titres for NEO and BVD, separated from others referring to energy and protein imbalance as high concentrations of BHB, low Chol and low Tp. However, SAA and Hp were not increased in aborted cows with clues of infectious diseases such as BVD, leptospirosis or neosporosis.

In this way, it is evident that when the causality of abortions in a herd is studied, not only is it necessary to look for infectious diseases, but non-infectious causes can also be found occurring in parallel way. Serum amyloid A could be a candidate biomarker to differentiate a non-infectious abortion.

\section{Acknowledgments}

We would like to gratefully acknowledge financial support from the FONDECYT Project № 11110090.

\section{Conflicts of Interest}

Authors declares that there is no conflict of interest.

\section{References}

1. Rivera H. Causas frecuentes de aborto bovino. Revista de Investigaciones Veterinarias del Perú. 2017;12(2):117-122.

2. Sundrum A. Metabolic disorders in the transition period indicate that the dairy cows' ability to adapt is overstressed. Animals. 2015;5(4):9781020 .

3. Benavides B, Jurado C, Cedeño D. Factores de riesgo asociados a aborto bovino en la cuenca lechera del departamento de Nariño. Rev Mvz Córdoba. 2010;15(2):2087-2094.

4. Gädicke P, Monti G. Aspectos epidemiológicos y de análisis del síndrome de aborto bovino. Arch Med Vet. 2008;40(3):223-234.

5. Wittwer F. Valores referenciales bioquímicos sanguíneos en animales de granja. In: Witter M, Fernando GV (Eds.), Chile: Manual de Patología Clínica Veterinaria. 2012;p:200.

6. Gädicke P. Síndrome de aborto bovino: análisis de sus componentes. Editorial Académica española. Saarbrücken, Deutschland: Bahnhofstrad $\beta$ e. 2016;28: 66111.

7. Keshavarzi H, Sadeghi SA, Stygar AH, et al. Effects of abortion and other risk factors on conception rate in Iranian dairy herds. Livest Sci. 2017;206:51-58

8. Ceciliani F, Ceron JJ, Eckersall PD, et al. Acute phase proteins in ruminants. J Proteomics. 2012;75(14):4207-4231.

9. Eckersall PD, Bell R. Acute phase proteins: biomarkers of infection and inflammation in veterinary medicine. Vet J. 2010;185(1):23-27.

10. Servicio Agrícola y Ganadero (SAG). Informe: Síndrome de aborto bovino, 2008-2011. Boletín Veterinario Oficial. 2011;14: 1-5.

11. Fernández ME, Campero CM, Morrell E, et al. Pérdidas reproductivas en bovinos causadas por abortos, muertes prematuras, natimortos y neonatos: casuística del período 2006-2007. Rev Med Vet. 2007;88:246254.

12. Luna ML, Roldan V. Perfil mineral en bovinos lecheros de Santa Fe, Argentina. Rev Vet. 2013;24(1): 47-52.

13. Norman HD, Miller RH, Wright JR, et al. Factors associated with frequency of abortions recorded through Dairy Herd Improvement test plans. J Dairy Sci. 2012;95(7):4074-4084.

14. Newcomer BW, Cofield LG, Walz PH, et al. Prevention of abortion in cattle following vaccination against Bovine Herpesvirus 1: A meta-analysis. Prev Vet Med. 2017;138:1-8.

15. Borel N, Frey CF, Gottstein B, et al. Laboratory diagnosis of ruminant abortion in Europe. Vet J. 2014;200(2):218-229.

16. Gädicke P, Monti G. Factors related to the level of occurrence of bovine abortion in Chilean dairy herds. Prev Vet Med. 2013;110(2):183-189.

17. Klamminger S, Prunner I, Giuliodori MJ, et al. Uterine infection with bovine herpesvirus type 4 in dairy cows. Reprod Domest Anim. 2017;52(1):115-121.

18. Chagas LM, Bass JJ, Blache D, et al. Invited Review: New Perspectives on the Roles of Nutrition and Metabolic Priorities in the Subfertility of HighProducing Dairy Cows. J Dairy Sci. 2007;90(9):4022-4032.

19. Erb HN, Smith RD, Oltenacu PA, et al. Path model of reproductive disorders and performance, milk fever, mastitis, milk yield, and culling in Holstein cows. J Dairy Sci. 1985;68(12):3337-3349.

20. Ruprechter G, Maria DLA, Larriestra A, et al. Metabolic predictors of peri-partum diseases and their association with parity in dairy cows. Res Vet Sci. 2018;118:191-198. 
21. Clothier K, Anderson M. Evaluation of bovine abortion cases and tissue suitability for identification of infectious agents in California diagnostic laboratory cases from 2007 to 2012. Theriogenology 2016;85(5):933938.

22. Trevisi E, Minuti A. Assessment of the innate immune response in the periparturient cow. Res Vet Sci. 2017;116:47-54.
23. Wael ED, Ibrahim G, Mahmoud F, et al. Acute phase proteins, proinflammatory cytokines and oxidative stress biomarkers in sheep, goats, and she-camels with Coxiella burnetii infection induced abortion. Comp Immunol Microbiol Infect Dis. 2019;67:101352.

24. Chen L, Deng $\mathrm{H}$, Cui $\mathrm{H}$, et al. Inflammatory responses and inflammationassociated diseases in organs. Oncotarget. 2018;9(6):7204-7218. 